\title{
Minimum Quantity Lubrication While using Nano Crystalline Graphite Powder as Lubricant in Surface Grinding
}

\author{
M.Raja Sekhara Rao, N.V.Jaswanth, V.S.Parameswara Rao
}

\begin{abstract}
The man or woman of an object is impacted with the useful resource of the surface honesty gotten via crushing activities. Pounding is one of the maximum prevalently utilized floor completing procedure portrayed with the aid of top notch manner talents as some distance as floor crowning glory and fabric evacuation price. besides it wishes tremendously immoderate specific power and gives ascend to fantastically excessive temperature, which finally ends up into excessive final anxieties, smaller scale splits and eat that is beaten with the aid of utilizing coolants on this manner lessening rubbing and giving possible cooling of work-wheel interface. Use of widespread coolants is in most instances incapable due to unavailability of the liquid to pounding vicinity and movie bubbling. A huge lot of the regular coolants gift fitness risk and bolster nursery effect. the inducement inside the returned of this exam is to analyze the base quantity of grease to be carried out at the AISI 52100 bearing metallic with the aid of the use of severa period nano particles. it is visible that the usage of nano particles as ointments is advanced to the traditional dry and moist oil. there's an in depth abatement in the temperature and a putting exchange inside the nature of the ground as a long way as floor harshness is widespread. This creation clarifies the usage of Palm oil as conveying medium and nano crystalline graphite powder as grease.
\end{abstract}

Key words:- Nano lubrication, Particle size, Surface finish, Vegetable oil

\section{INTRODUCTION}

The assignment of current producing organizations to usually decrease machining charges and beautify the person of the machined elements has brought on the development in distinctive machining viewpoints. particularly, machining of difficult substances is a mind boggling surprise which results in awful surface of entirety, high instrument put on, premature disappointment of cutting devices because of high temperature age, constructed-up-side (BUE) development and so forth. one of the methods for coping with the warmth age on the tool chip interface is with the aid of manner of the use of valid grease [1]. in the direction of latest a long time, the oil innovation has been basically changed due to a mixture of herbal, health, monetary, and execution demanding situations $[1,2]$. To deal with those problems, it is easy to create and execute greases and oil bureaucracy. A portion of the optional methodologies are utilising bio degradable and cryogenic coolants $[3,5]$. The concept of

Revised Manuscript Received on April 12, 2019.

M.RajaSekharaRao, Faculty, Higher college of Tech., Muskat, Oman Ch.N.V.Jaswanth, M.Tech student, NTTF, Bangalore, Karnataka, India.

Ch.V.S.ParameswaraRao, Prof., Narayana Engg.college, Gudur524101, A.P, India. minimum quantity Lubrication (MQL) is utilized as an non-obligatory technique. research are being completed within the vicinity of eco-accommodating comparatively cheap assembling, making use of easy machining techniques, the use of least amount of ointment such MoS2 powder and graphite combined with water and SAE 40 oil in unique extents in place of flood coolant [6,7]

Graphite is one of the most famous sturdy oils which has exceptional grease residences and is right away on hand. a few investigations diagnosed with the oil properties of graphite are finished in the direction of latest decades $[2,6]$. these examinations essentially targeted throughout the exhibition of graphite in high temperature packages. The investigations confirmed that graphite's precise hexagonally prepared planar layered shape makes it a truly encouraging robust oil cloth. The houses of graphite are exhibited in desk 1. one of the policies of utilising dry graphite powder in machining approaches is the manner that it should be consistently "splashed" into the device workpiece touch interface. the kind of bathe framework, but is plenty less cc718adab7499529b227d0ea7ca018fe, does no longer talk to a realistic oil optional for industry [4, 8]. a few professionals have made a selected file on using a sturdy oil combination like graphite in SAE 40 oil and boric corrosive in SAE 40 oil in the turning of different steels. Exploratory consequences are observed to energize with a few lower in slicing powers and ground unpleasantness at the same time as contrasted with dry and wet machining. Graphite, as an oil applied in crushing, has demonstrated promising consequences as far as warmth age on the granulating region. research have announced the usage of strong oils to interrupt down the impact of numerous machining parameters and its conduct as for the particulate duration of the strong oil. they've observed out an contrary connection between grinding coefficient and robust grease particulate size. Boric corrosive powder changed into implemented to direct Pin on Disk (PoD) find out specific avenues regarding crystalline length going from $350 \mu \mathrm{m}$ to $100 \mathrm{~nm} \mathrm{[7,8}$ and 9]. because the residences of substances alternate regarding spatial measurements from micron to nano estimate, the tribological execution of the robust oil implemented in steel cutting has became out to be improper $[10,11]$. 
The present paintings intends to endure in thoughts the effect of sturdy grease helped crushing way, the usage of nano-crystalline graphite powder as oil and with Palm oil as a conveying medium and the concept of minimum quantity Lubrication (MQL). Schematic portrayal is regarded in Fig.1 (an) and it's far implemented to improve using greases. Fig. 1 (b) speaks to the exploratory arrangement. Examinations are led on AISI $52100[6,8]$ bearing metallic utilising aluminum oxide crushing wheel [7,9], to observe the viability of strong ointment helped pounding under thing machining situations. beginning trials are likewise directed to find out the appropriate weight degree of the ointment powder to be blended in the conveying medium.

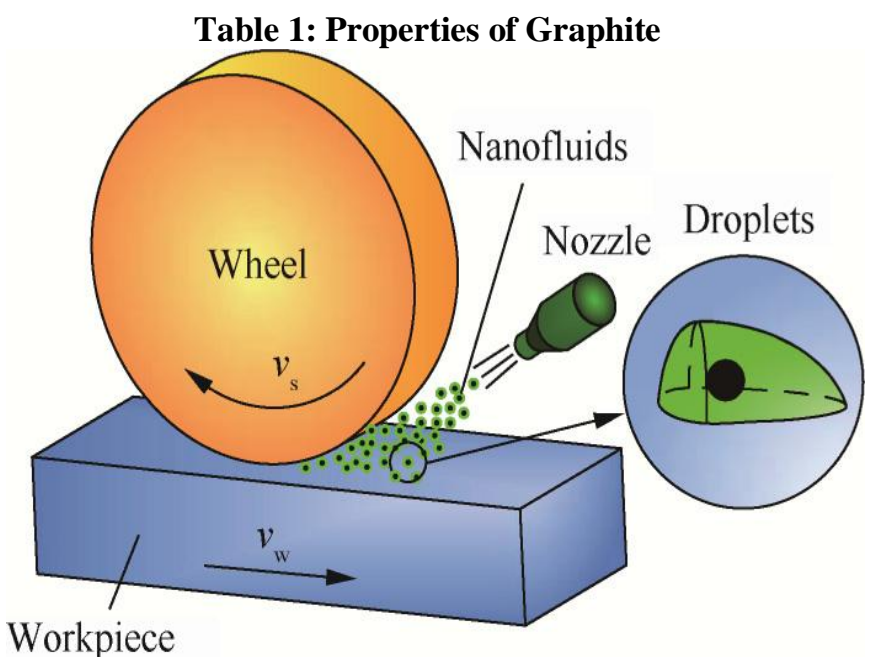

Fig. 1(a) Schematic representation of nano particle jet MQL

\section{EXPERIMENTATION}

Starting experimentation consists of the finding of least quantity oil i.e the bottom measure of nano molecule to be combined within the conveying medium. The impact of the nano crystalline powder is broke down with the aid of the usage of contrasting it and dry crushing and via the usage of utilizing crude Palm oil which in the later degrees is carried out as conveying medium. The investigations had been caused contemplate the effect of nano-particulate graphite powder as a grease in pounding responsibilities. Parameters like temperature and floor unpleasantness are taken into consideration as the yield parameters.

The examinations are led via apportioning the ointment at the rate of four $\mathrm{ml} / \mathrm{min}$. [7] onto the focused on zone. Emulsifying tools comprising of a repository and a stirrer is produced for administering the grease required in the course of machining and for preserving up the physical united states of the oil. The capability of the stirrer is to cope with agglomeration of the ointment mixture. at the start, Palm oil and graphite powder is altogether mixed utilising an appealing stirrer and stuffed the repository. The specific records parameters taken into consideration are the profundity of reduce, weight stage of the nano debris mixed inside the conveying medium and the molecule sizes of the nano crystalline graphite powder. The temperature is expected utilizing a Temperature

\begin{tabular}{|c|c|c|c|}
\hline Structure & Lamellar & $\begin{array}{l}\text { Modulus of } \\
\text { Elasticity (GPa) }\end{array}$ & $8-15$ \\
\hline $\begin{array}{l}\text { Friction } \\
\text { Coefficient }\end{array}$ & $0.22-0.4$ & $\begin{array}{l}\text { Compressive } \\
\text { strength (MPa) }\end{array}$ & $20-200$ \\
\hline $\begin{array}{l}\text { Bulk Density } \\
\left(\mathrm{g} / \mathrm{cm}^{3}\right)\end{array}$ & $1.3-1.95$ & $\begin{array}{ll}\text { Flexural strength } \\
(\mathrm{MPa})\end{array}$ & $6.9-100$ \\
\hline Porosity (\%) & $0.7-53$ & $\begin{array}{l}\text { Coefficient } \\
\text { Thermal } \\
\text { Expansion } \quad(x 10 \\
\\
\left.{ }^{60} \mathrm{C}\right)\end{array}$ & $1.2-8.2$ \\
\hline $\begin{array}{|lr|}\text { Specific } & \text { heat } \\
\text { capacity } & (\mathrm{J} / \mathrm{kg} \\
\mathrm{K}) & \\
\end{array}$ & $710-830$ & $\begin{array}{l}\text { Thermal } \\
\text { conductivity } \\
(\mathrm{W} / \mathrm{m} . \mathrm{K})\end{array}$ & $25-470$ \\
\hline Melting Point & $3600^{\circ} \mathrm{C}$ & Boiling Point & $4200^{\circ} \mathrm{C}$ \\
\hline
\end{tabular}

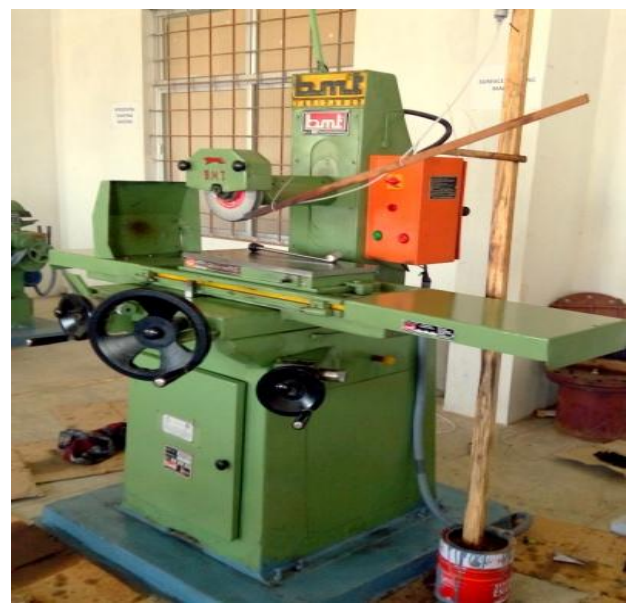

Fig. 1(b) Experimental setup

weapon (Fig. 2) directed to the pounding place. An adjusted surface roughness tester (Talysurf) is employed (Fig. 3) to measure the average surface roughness $\left(R_{a}\right)$.

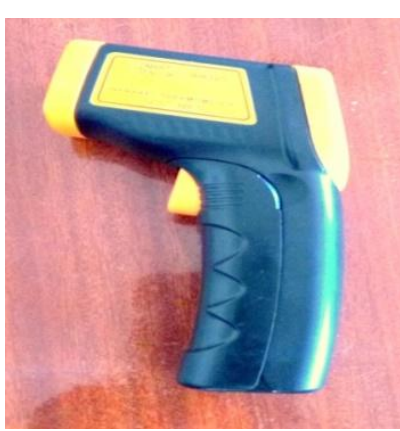

Fig. 2: Temperature Gun

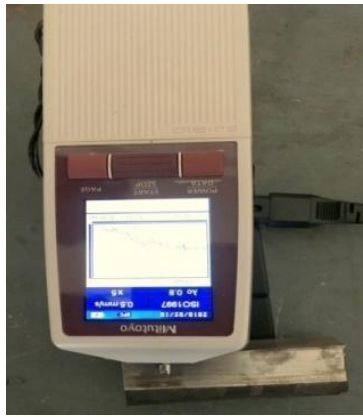

Fig. 3: Surface Roughness Tester
The primer investigations included the utilizing unadulterated Palm oil and by dry granulating. Machining was completed for four minutes. The test brings about terms of temperature and surface unpleasantness are introduced in Fig. 4. what's more, classified in Table.2. It is seen that the temperature and surface unpleasantness esteems are better while utilizing Palm oil when contrasted with dry pounding process.

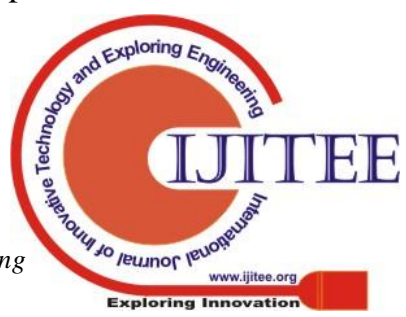




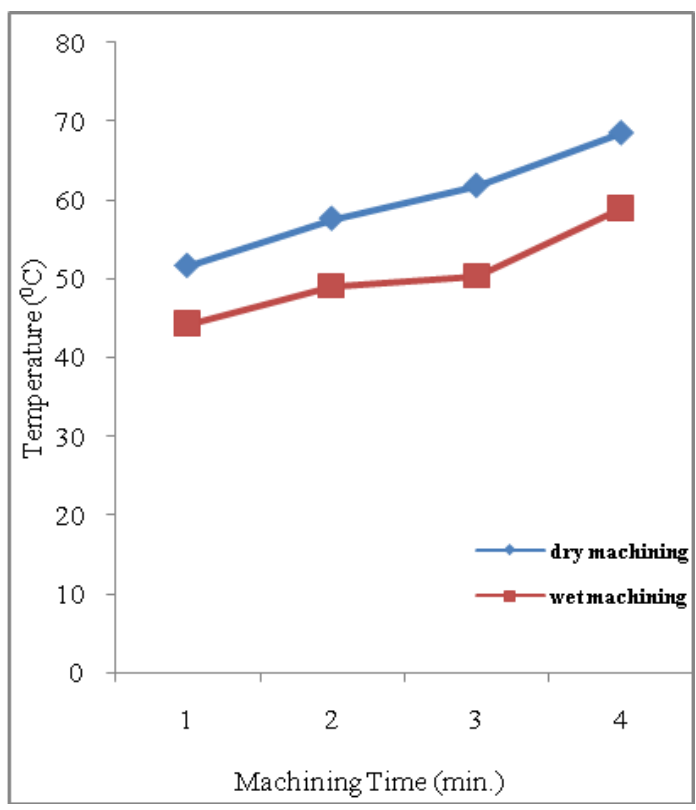

(a)

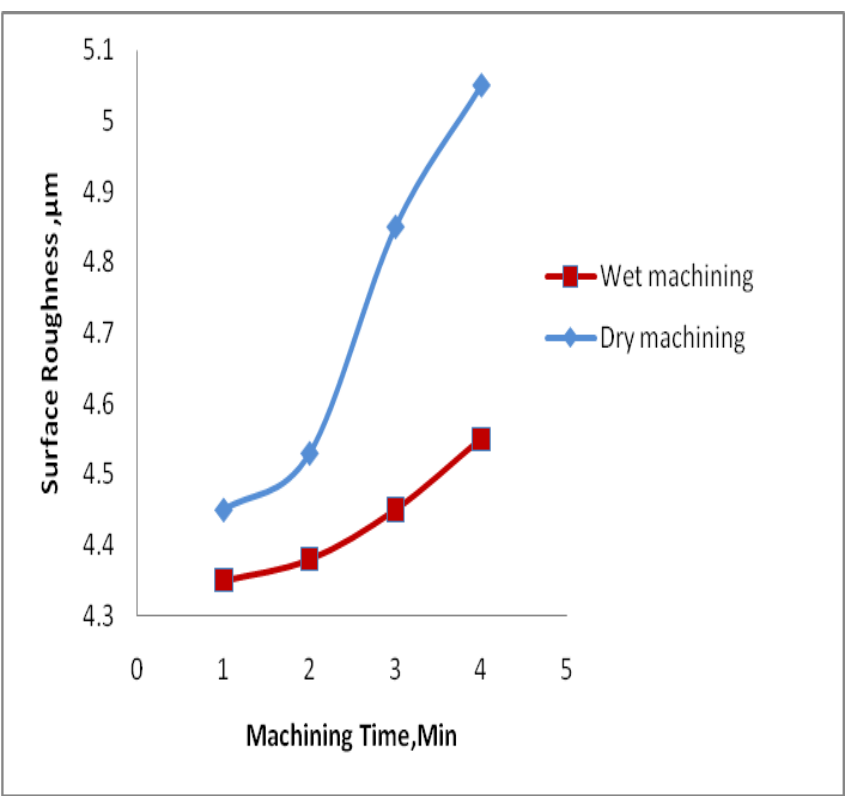

(b)

Fig: 4: Experimental results pertaining to dry and wet lubrication Temperature in ${ }^{\circ} \mathrm{c}$ and (b) Surface Roughness in $\mu \mathrm{m}$

Table 2 Average values of Dry and Wet Machining

\begin{tabular}{|l|c|c|}
\hline $\begin{array}{c}\text { AVERAGE } \\
\text { VALUES }\end{array}$ & $\begin{array}{c}\text { DRY } \\
\text { MACHINING }\end{array}$ & $\begin{array}{c}\text { WET } \\
\text { MACHINING }\end{array}$ \\
\hline Temperature & 59.88 & 50.63 \\
\hline Surface Roughness & 4.73 & 4.46 \\
\hline
\end{tabular}

\section{EXPERIMENTAL RESULTS}

Starting experimentations were completed to decide the suitable degree of nano-particulate sturdy grease to be blended inside the conveying medium. The machining conditions taken into consideration are $2700 \mathrm{rpm}$ of slicing pace and with a feed charge of $15 \mathrm{~mm} / \mathrm{rev}$. The profundity of cut turn out to be saved at $0.2 \mathrm{~mm}$. the example weight prices of the powder considered were zero. $5 \%, 1 \%, 2 \%$, three $\%, 4 \%$ and five $\%$ in sixteen $\mathrm{ml}$ of Palm oil. As noticed from Fig. 5, with the weight stage of strong ointment inside the conveying medium is elevated, the deliberate parameter temperature is increasing. At 3\% of the robust oil inside the conveying medium, the growth in the planned characteristics settles because of this there may be no growth inside the planned parameters with the increment within the strong ointment in the conveying medium. The qualities are the least when $1 \%$ of nanoparticulate graphite powder is applied. consequently, similarly experimentation is completed through including $1 \%$ of nano-particulate graphite powder in the conveying medium. it is likewise visible that with the boom inside the molecule measure, the temperature diminishes.

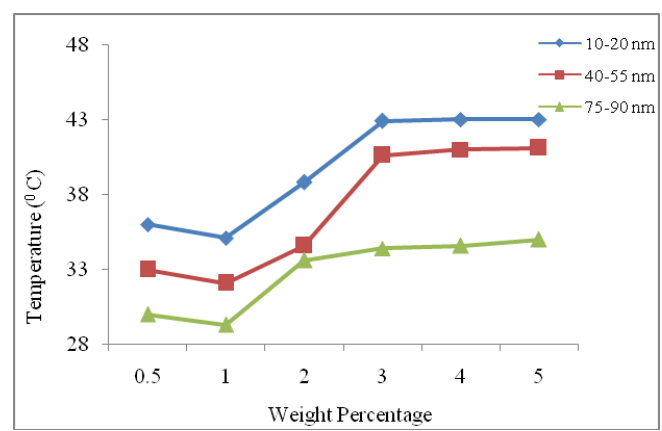

Fig. 5 Effect of particle size on temperature

Fig. 6 represents the impact of version of particle size of the strong lubricant at the surface excellent. it is determined that the particle length increases, the floor high-quality improves. it is really seen that with a weight percentage of one \%, the floor roughness cost is minimum. for this reason the first-rate surface end acquired is at a concentration of one $\%$ of the nano crystalline powder within the sporting medium. The consequences are depicted in desk 3.

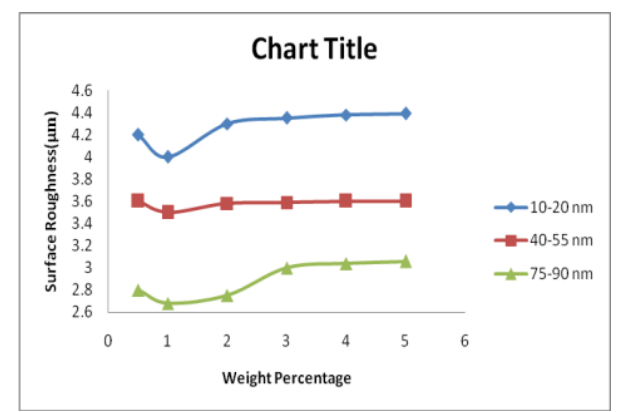

Fig. 6 Effect of particle size on Surface Roughness 
Table 3 Average values at $1 \%$ weight concentration

\begin{tabular}{|c|l|l|}
\hline $\begin{array}{c}\text { PARTICLE } \\
\text { SIZE }\end{array}$ & $\begin{array}{c}\text { TEMPERATURE, } \\
{ }^{\circ} \mathrm{C}\end{array}$ & $\begin{array}{c}\text { SURFACE } \\
\text { ROUGHNESS, } \\
\text { Ra, } \mu \mathrm{m}\end{array}$ \\
\hline $10-20 \mathrm{~nm}$ & 35.1 & 4.02 \\
\hline $40-55 \mathrm{~nm}$ & 32.1 & 3.5 \\
\hline $75-90 \mathrm{~nm}$ & 29.3 & 2.7 \\
\hline
\end{tabular}

\section{CONCLUSIONS}

The present nation of grease inside the floor granulating process affirmed the adequacy of the utilization of nano debris as ointment in crushing process. The examination of this inspect demonstrates that the manner parameter period of the nano-arrange graphite powder is impacting factors which have an impact on the temperature and display the degree of surface harshness got. The take a look at canvases can be a stimulus to create diagnostic patterns, essentially primarily based at the exploratory consequences to are anticipating the general styles of workpiece floor harshness and temperature. The take a look at insights gives a view of the effect of nano-degree variety inside the molecule length of graphite powder within the meantime as pounding AISI 52100 steel. As determined from the experimentation, the ideal degree of nano particulate graphite powder to be consolidated in the conveying medium is $1 . z e r o \%$. The temperature progressed with the decrease in the molecule length of the grease utilized which underscores the decrease in its exhibition in its nano measurements. The ground end of the wok fabric has decayed. this may be credited to the blast in temperatures and scouring. the cutting-edge trial characteristic admirably knownshows a reverse marvel within the nano device of the constant ointment molecule size utilized. it may as a result be reasoned that the heap percent of nano-particulate graphite powder within the carrying medium need to be least whilst being utilized as an ointment or all matters considered there might be a big development inside the temperature which additionally affects the ground cease of the component.

\section{ACKNOWLEDGEMENTS}

The authors acknowledge the PBR VITS, Kavali for extending the machining and measuring facilities in their labs.

\section{REFERENCES}

1. B. Shen, A.J. Shih, minimal quantity oil (MQL) pounding making use of vitrified CBN wheels, Transactions of NAMRI/SME 37, 29-136, 2009.

2. R. Wojcik, application of latest types of cooling media and offering techniques for the duration of floor pounding, files of Mechanical technology and Automation 28 (4), 137-100 45, 2008.

3. I.D. Marinescu, M. Hitchiner, E. Uhlmann, W.B. Rowe, I. Inasaki, guide of Machining with Grinding Wheels, CRC Press, Boca Raton, 359-410, 2007

4. F. Klocke, A. Baus, T. Beck, Coolant incited powers in CBN rapid pounding with shoe spouts, Annals of the CIRP 49 (1), 241-244, 2000.

5. E. Brinksmeier, T. Brockhoff, A. Walter, minimum amount grease in granulating, methods of the second one global
Machining and Grinding conference, SME, MI, america of the united states, 639-654, 1997

6. J. Webster, choice of coolant kind and alertness approach in granulating, in: excellent overwhelm 1995 - Grinding and sharpening with brilliant abrasives, Connecticut, u.s.a.a., 205-220, 1995

7. S. Saji, V. Radhakrishnan, An exam on floor crushing utilizing graphite as oil, worldwide magazine of device system and Manufacture 40, 733-740, 2002.

8. E. Brinksmeier, C. Heinzel, M. Wittmann, Friction, cooling and grease in granulating, CIRP Annals: production era 48 (2), 581-598, 1999.

9. M. Alberts, good enough. Kalaitzidou, S. Melkote, An exam of graphite nano platelets as oil in granulating, international magazine of tool gear and Manufacture forty nine, 966-970, 2009

10. M.L. Harmann, Abrasive article, US Patent 1615271, 1927.[11] okay. Nadolny, W. Sienicki, M. Wojtewicz, The effect upon the crushing wheel dynamic floor circumstance at the same time as impregnating with non-metal components at some point of indoors tube fashioned granulating of titanium, files of Civil and Mechanical Engineering, 2014 